OPEN ACCESS

Edited by:

Alfredo Conti,

University of Bologna, Italy

Reviewed by:

Dong Liu,

Tianjin Medical University, China

David Mathieu,

Université de Sherbrooke, Canada

Zhiyuan Xu,

University of Virginia, United States

${ }^{*}$ Correspondence:

Jinxiu Yu

josse_yu@foxmail.com

${ }^{t}$ These authors have contributed equally to this work

Specialty section: This article was submitted to Neuro-Oncology and

Neurosurgical Oncology, a section of the journal

Frontiers in Oncology

Received: 25 August 2020 Accepted: 20 October 2020 Published: 24 November 2020

Citation:

Fu J, Wu L, Peng C, Yang $X$, You $H$,

Cao L, Deng Y and Yu J (2020) Initial Gamma Knife Radiosurgery for Large or Documented Growth Asymptomatic Meningiomas: Long-Term Results From a 27-Year Experience.

Front. Oncol. 10:598582. doi: 10.3389/fonc.2020.598582

\section{Initial Gamma Knife Radiosurgery for Large or Documented Growth Asymptomatic Meningiomas: Long-Term Results From a 27-Year Experience}

Junyi $\mathrm{Fu}^{1 \dagger}$, Lisha $\mathrm{Wu}^{2 \dagger}$, Chao Peng ${ }^{3 \dagger}$, Xin Yang ${ }^{4 \dagger}$, Hongji You ${ }^{5}$, Linhui Cao ${ }^{6}$, Yinhui Deng ${ }^{7}$ and Jinxiu $Y u^{7 *}$

\footnotetext{
${ }^{1}$ Department of Neurology, The Second Affiliated Hospital of Guangzhou Medical University, Guangzhou, China, ${ }^{2}$ Department of Medical Oncology, Sun Yat-sen Memorial Hospital, Sun Yat-sen University, Guangzhou, China, ${ }^{3}$ Department of Neurosurgery, Guangdong Provincial People's Hospital, Guangdong Academy of Medical Sciences, Guangzhou, China, ${ }^{4}$ Department of Thoracic Surgery, The Second Affiliated Hospital of Guangzhou Medical University, Guangzhou, China, ${ }^{5}$ Department of Nuclear Medicine, The Second Affiliated Hospital of Guangzhou Medical University, Guangzhou, China, ${ }^{6}$ Department of Traditional Chinese Medicine, Sun Yat-sen Memorial Hospital, Sun Yat-sen University, Guangzhou, China, ${ }^{7}$ Department of Radiotherapy, The Second Affiliated Hospital of Guangzhou Medical University, Guangzhou, China
}

Objective: The aims of this study were to investigate the long-term outcomes of initial Gamma Knife radiosurgery (GKRS) for large $(\geq 20 \mathrm{~mm})$ or documented growth asymptomatic meningiomas.

Design and Methods: This was a single-center retrospective study. Fifty-nine patients with large $(\geq 20 \mathrm{~mm}$ ) or documented growth asymptomatic meningiomas undergoing initial GKRS were enrolled. The median age was 56 (range, 27-83) years. The median time of follow-up was 66.8 (range, 24.6-245.6) months, and the median tumor margin dose was 13.0 Gy (range, 11.6-22.0 Gy).

Results: Tumors shrunk in 35 patients (59.3\%) and remained stable in 23 (39.0\%). One patient (1.7\%) experienced radiological progression at 54 months after GKRS. The PFS was $100 \%, 97 \%$, and $97 \%$ at 3,5 , and 10 years, respectively. Nine patients (15.3\%) occurred new neurological symptoms or signs at a median time of 8.1 (range, 3.0-81.6) months. The symptom PFS was $90 \%$ and $78 \%$ at 5 and 10 years, respectively. Fifteen patients (25.4\%) occurred peritumoral edema (PTE) at a median time of 7.2 (range, 2.0-81.6) months. One patient underwent surgical resection for severe PTE. In univariate and multivariate analysis, Only tumor size ( $\geq 25 \mathrm{~mm}$ ) and maximum dose ( $\geq 34 \mathrm{~Gy}$ ) were significantly associated with PTE [hazard ratio $(H R)=3.461,95 \%$ confidence interval $(\mathrm{Cl})=1.157-10.356, p=0.026$ and $\mathrm{HR}=3.067,95 \% \mathrm{Cl}=1.068-8.809, \mathrm{P}=0.037$, respectively].

Conclusions: In this study, initial GKRS can provide a high tumor control rate as well as an acceptable rate of complications in large or documented growth asymptomatic 
meningiomas. GKRS may be an alternative initial treatment for asymptomatic meningiomas.

Keywords: peritumoral edema, gamma knife, stereotactic radiosurgery, asymptomatic meningioma, progressionfree survival

\section{INTRODUCTION}

Meningiomas are the most common intracranial benign tumors, which represent almost $13 \%-37.6 \%$ of all intracranial tumors (14). Of those meningiomas with documented WHO grade, $80.5 \%$ are grade I, $17.7 \%$ are grade II and $1.7 \%$ are grade III (4). As a result of advancement and increased application in magnetic resonance imaging (MRI) and computed tomography (CT), detection of asymptomatic meningiomas is becoming increasingly prevalent. Initial managements for asymptomatic meningiomas include observation, surgical resection and radiotherapy. However, the best treatment still remains controversial.

In most instances, many asymptomatic meningiomas has an indolent natural course. Only a small proportion of patients become symptomatic. In previous studies, $24 \%-92 \%$ of those meningiomas will increase in size under observation after a period of more than 4 years $(1,2,5-10)$. Observation is a reasonable treatment option for those slow-growing and small asymptomatic tumors. But it may increase the treatment risk due to enlarged tumors and patient age. In a population-based analysis, the use of primary observation increased for smaller tumors $(<2 \mathrm{~cm})$, relative to surgery and radiation (11). In a recent meta-analysis, those tumors with larger size were likely to be symptomatic (12). Therefore, treatment should be recommended for large tumors, symptomatic tumors and those documented growth. Surgical resection is a better choice for tumor removal. But it is an invasive treatment, depends on tumor location and can cause significant morbidity (13). Gamma knife radiosurgery (GKRS) is more appealing than surgical resection, which is a less invasive treatment with a low morbidity.

There had been several publications reported the efficacy and safety of GKRS as primary or adjuvant treatment for asymptomatic meningiomas. These results showed a low tumor progression rate of $0-5.9 \%$, and an acceptable rate of complications ranged from $2.4 \%$ to $20.5 \%$ after GKRS ( 7,10 , $14,15)$. However, many patients in these studies had prior surgery or radiotherapy, peritumoral edema (PTE) or small tumors $(<20 \mathrm{~mm})$. The long-term outcomes of initial GKRS for asymptomatic meningiomas still need to be demonstrated. Therefore, we performed a single-center retrospective study consisting of patients with previous untreated, non-PTE and mainly large ( $\geq 20 \mathrm{~mm}$ ) asymptomatic meningiomas.

\section{METHODS}

\section{Patients Population}

The medical records of meningioma patients from the singlecenter that underwent GKRS between December 1993 and December 2017 were retrospectively reviewed. There were 340 patients had complete clinical data and sufficient follow-up $(\geq 24$ months) in our hospital. Finally, 59 patients were included in this study. The GKRS inclusion criteria were shown in Figure 1. This study was approved by the institutional committee of the Second Affiliated Hospital of Guangzhou Medical University.

Inclusion criteria of this study: 1) MRI and/or CT findings suggested the diagnosis of meningioma, as interpreted by experienced clinicians and radiologists; 2) tumors with homogeneously contrast enhancement, dural tail and no perilesional edema; 3) the initial treatment was GKRS, no prior surgery or radiotherapy for the meningiomas; 4) no neurological symptoms or signs caused by the tumor; 5) large tumors $(\geq 20$ $\mathrm{mm}$ ), or those small tumors with documented growth were included; 6) all of patients had complete medical records, at least one radiological and clinical evaluations with minimum follow-up of 24 months. Patients with neurofibromatosis type 2associated meningiomas and PTE were excluded.

\section{Radiological and Clinical Evaluations}

All of asymptomatic meningioma patients were required to take routine clinical and radiological follow-up evaluations at 6 months initially and thereafter yearly. The follow-up evaluations were evaluated by experienced clinicians and radiologists. Tumor volume was based on $\mathrm{ABC} / 2$ formula: (A) maximum tumor diameter on axial plane; (B) diameter perpendicular to (A), and (C) maximum height on sagittal/ coronal plane (16). Tumor shrinkage was defined as a reduction in tumor size at least $20 \%$ in any diameter. Stable tumor was defined as a change in tumor size within $20 \%$ in any diameter. Tumor progression was defined as an increase in tumor size at least $20 \%$ in any diameter. New neurological symptoms or sighs after GKRS were recorded. Radiation related adverse effects and requiring treatment were reported.

\section{Gamma Knife Radiosurgery Technique}

Before April 2014, all of the patients were treated with Leksell Gamma Knife Unit B. Leksell Gamma Knife Perfexion Unit (Elekta Instrument, Inc.) was used from April 2014 to the present. Patients were placed with Leksell stereotactic frame $G$ and underwent stereotactic MR imaging with contrast through the entire brain for target delineation. GKRS plan was designed by a radiation oncologist, medical physicist, and neurosurgeon. 4 or $8 \mathrm{~mm}$ collimator was used for better conformality.

\section{Statistical Analysis}

IBM's SPSS (version 21.0) was used for statistical analyses. Univariate and multivariate analysis of risk factors associated with PTE after GKRS and symptom progression were carried out with Log-rank test statistics and a step forward likelihood ratio method of Cox proportional hazard models respectively. Kaplan- 


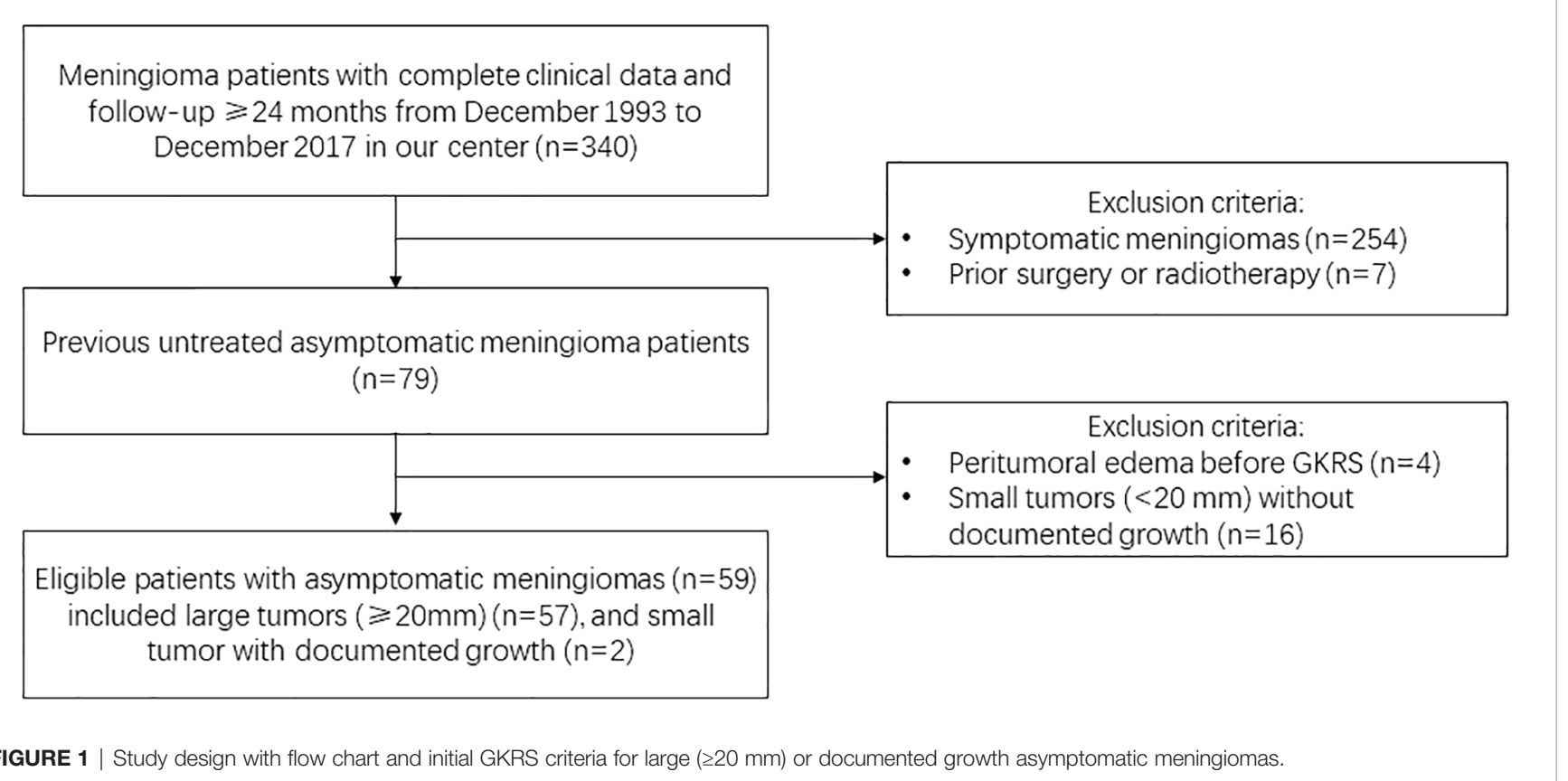

Meier curves were plotted for progression-free survival (PFS), PTE and symptom progression. Probability values $<0.05$ were defined as statistically significant.

\section{RESULTS}

\section{Patient Characteristics}

Characteristics of patients were showed in Table 1. Fifty-nine patients who met inclusion criteria were included in this study. Of the 59 patients, 15 (25.4\%) were male and 44 (74.6\%) were female. The median age was 56 (range, 27-83) years. The median time of follow-up was 66.8 (range, 24.6-245.6) months. The median size was 22.0 (range, 15.7-57.0) $\mathrm{mm}$. The median tumor volume was 3.9 (range, 2.5-6.8) $\mathrm{ml}$. Two patients with tumor size $<20 \mathrm{~mm}$ were documented with tumor growth on radiologic surveillance and enrolled in this study. The number of tumor size $\geq 30 \mathrm{~mm}$ was 12 (20.3\%). The falx/parasagittal region was the most frequent tumor location, followed by the middle fossa (sphenoid/parasellar).

All of patients underwent single fraction GKRS as initial treatment for meningiomas. The median margin dose was 13.0 (range, 11.6-20.0) Gy at a median prescription isodose $40 \%$ (range, 35\%-55\%). The median maximum dose was 32.0 (range, 25.1-50.0) Gy (Table 1).

\section{Radiological and Symptom PFS}

Overall, 58 patients $(98.3 \%)$ were confirmed as tumor control after a median follow-up time of 66.8 (range, 24.6-245.6) months. Tumors shrunk in 35 patients $(59.3 \%)$ and remained stable in 23 patients (39.0\%). One patient (1.7\%) experienced radiological progression at 54 months after GKRS. The PFS was
TABLE 1 | Characteristics of 59 patients with 59 asymptomatic meningiomas and GKRS parameters.

\begin{tabular}{lc}
\hline Characteristic & Value \\
\hline Male/Female, n (\%) & $15 / 44(25.4 / 74.6)$ \\
Median age, (range), years & $56(27-83)$ \\
Median FU length, (range), months & $66.8(24.6-245.6)$ \\
Median tumor size, (range), mm & $22.0(15.7-57.0)$ \\
$<20$ mm, n (\%) & $2(3.4)$ \\
$<30$ mm, n (\%) & $45(76.3)$ \\
$\geq 30$ mm, n (\%) & $12(20.3)$ \\
Median tumor volume, (range), ml & $3.9(2.5-6.8)$ \\
Tumor location & \\
Convexity, n (\%) & $6(10.2)$ \\
CPA, n (\%) & $8(13.6)$ \\
Falx/parasagittal, n (\%) & $24(40.7)$ \\
Cavernous sinus, n (\%) & $1(1.7)$ \\
Tentorial, $n$ (\%) & $3(5.1)$ \\
Middle fossa (sphenoid/parasellar), n (\%) & $10(16.9)$ \\
Intraventricular, n (\%) & $2(3.4)$ \\
Frontobasal, n (\%) & $5(8.5)$ \\
GKRS parameters & \\
Median margin dose, (range), Gy & $13.0(11.6-20.0)$ \\
Median maximum dose, (range), Gy & $32.0(25.1-50.0)$ \\
Median prescription isodose, (range), \% & $40(35-55)$ \\
\hline FU, folow up; GKRS, $\%(\%)$ &
\end{tabular}

FU, follow up; GKRS, gamma knife radiosurgery; CPA, cerebellopontine angle.

$100 \%, 97 \%$, and $97 \%$ at 3, 5, and 10 years, respectively (Figure 2) (Table 2).

The symptom PFS was defined as the time interval between the time of occurrence of new neurological symptoms or signs and the time of GKRS in this study. Nine patients (15.3\%) occurred new neurological symptoms or signs after GKRS at a median time of 8.1 (range, 3.0-81.6) months. Of the nine patients, seven patients presented with new neurological symptoms or signs might be due to PTE. Another two patients 


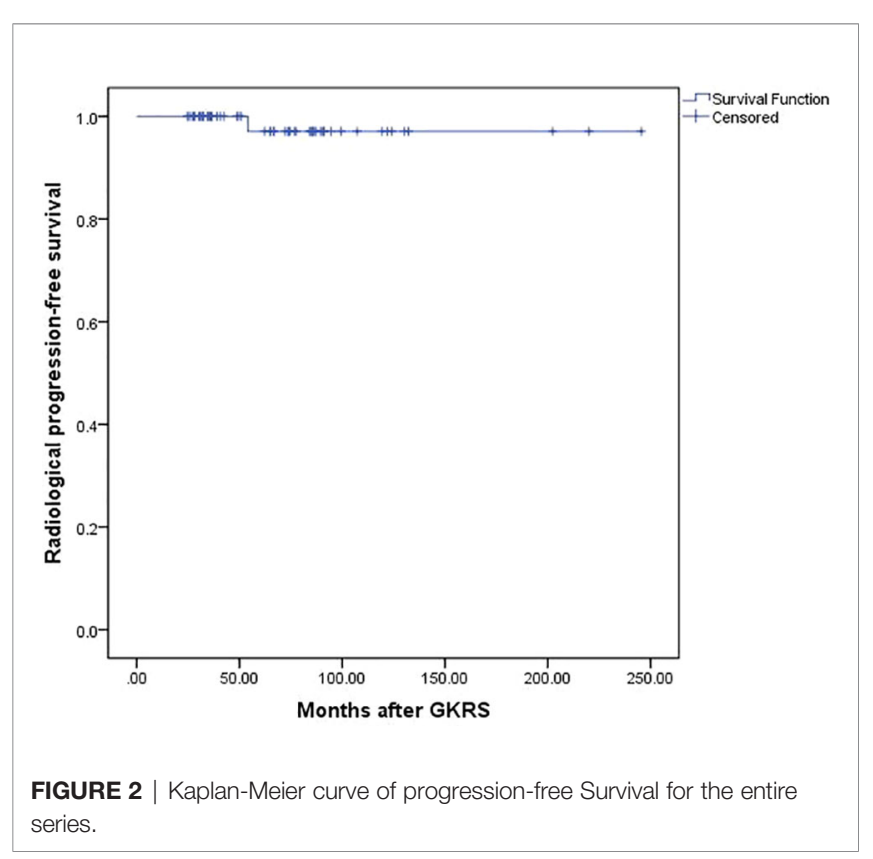

TABLE 2 | Outcomes of 59 patients with 59 asymptomatic meningiomas after initial GKRS.

\begin{tabular}{lc}
\hline Outcomes & value \\
\hline Tumor control & \\
Shrinkage, $\mathrm{n}(\%)$ & $35(59.3)$ \\
Stable, $\mathrm{n}(\%)$ & $23(39.0)$ \\
Progression, $\mathrm{n}(\%)$ & $1(1.7)$ \\
Complications after GKRS & $17(28.8)$ \\
Radiation-induced peritumoral edema & $15(25.4)$ \\
Symptomatic, $\mathrm{n}(\%)$ & $7(11.9)$ \\
Asymptomatic, $\mathrm{n}(\%)$ & $8(13.6)$ \\
Symptom unrelated with PTE & $2(3.4)$ \\
Memory loss & 1 \\
Cranial nerve deficit & 1 \\
\hline
\end{tabular}

presented with memory loss and cranial nerve deficit did not occur PTE after GKRS. The symptom PFS was $90 \%$ and $78 \%$ at 5 and 10 years, respectively (Figure 3) (Table 2).

\section{Complications After GKRS}

Seventeen patients (28.8\%) developed complications after GKRS, including 15 patients (25.4\%) with PTE and 2 patients with symptom unrelated with PTE. The median time of PTE was 7.2 (range, 2.0-81.6) months. Of these PTE patients, eight patients (13.6\%) were asymptomatic PTE. Another seven patients (11.8\%) presented with symptomatic PTE. Among of them, one patient underwent surgical resection for severe PTE after GKRS (Table 2). The rate of PTE after GKRS was 14\%, 24\%, and $24 \%$ at 6,12 , and 60 months, respectively (Figure 4).

Tumor size $(\geq 25 \mathrm{~mm})(\mathrm{p}=0.004)$, tumor volume $(\geq 5.3 \mathrm{ml})$ $(\mathrm{p}=0.038)$ and maximum dose $(\geq 34 \mathrm{~Gy})(\mathrm{p}=0.005)$ were associated with PTE in univariate analysis. Tumor size $(\geq 25$ $\mathrm{mm})$, maximum dose ( $\geq 34 \mathrm{~Gy})$, tumor volume $(\geq 5.3 \mathrm{ml})$ and tumor margin dose ( $\geq 14$ Gy) were included in multivariate analysis. Only tumor size ( $\geq 25 \mathrm{~mm}$ ) (Figure 5) and maximum

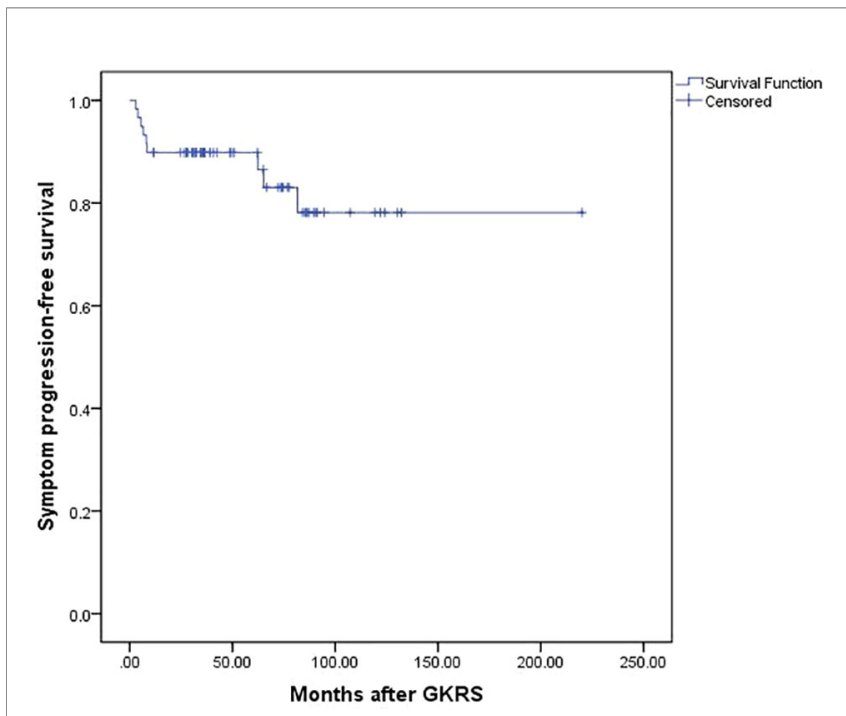

FIGURE 3 | Kaplan-Meier curve of Symptom progression-free survival for the entire series.

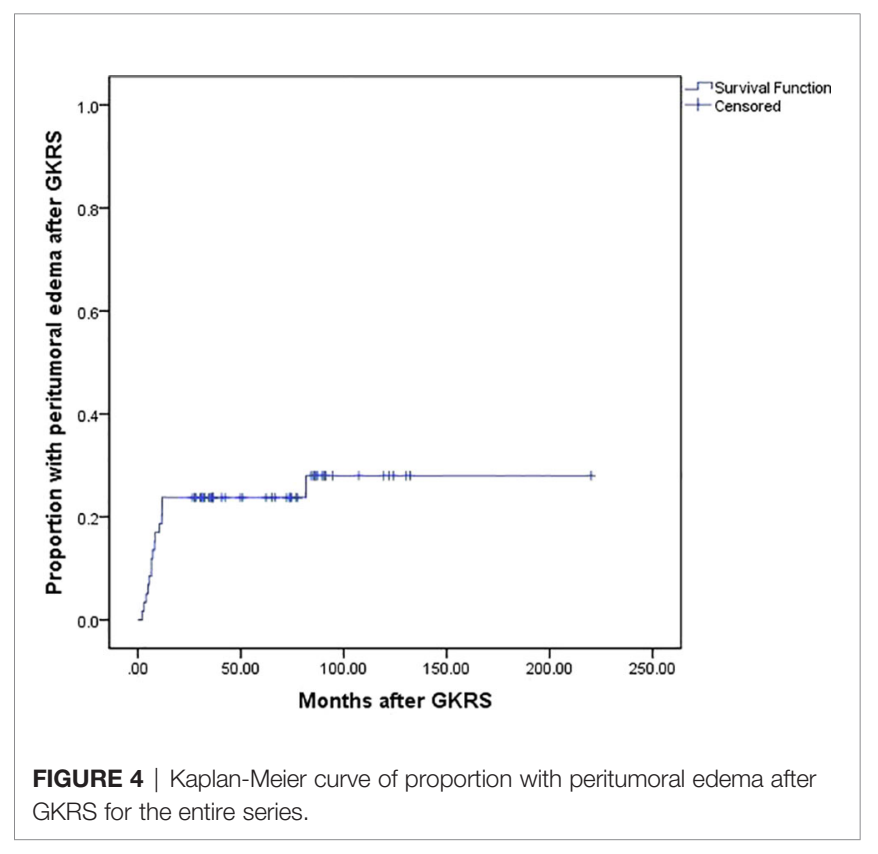

dose ( $\geq 34$ Gy) (Figure 6) were significantly associated with PTE [hazard ratio $(\mathrm{HR})=3.461,95 \%$ confidence interval $(\mathrm{CI})=1.157$ 10.356, $\mathrm{p}=0.026$ and $\mathrm{HR}=3.067,95 \% \mathrm{CI}=1.068-8.809, \mathrm{P}=0.037$, respectively] (Table 3 ).

\section{DISCUSSION}

\section{Natural History of Meningiomas}

As many asymptomatic meningiomas has an indolent natural course. Understanding the natural history of them is of great importance to make appropriate management. 


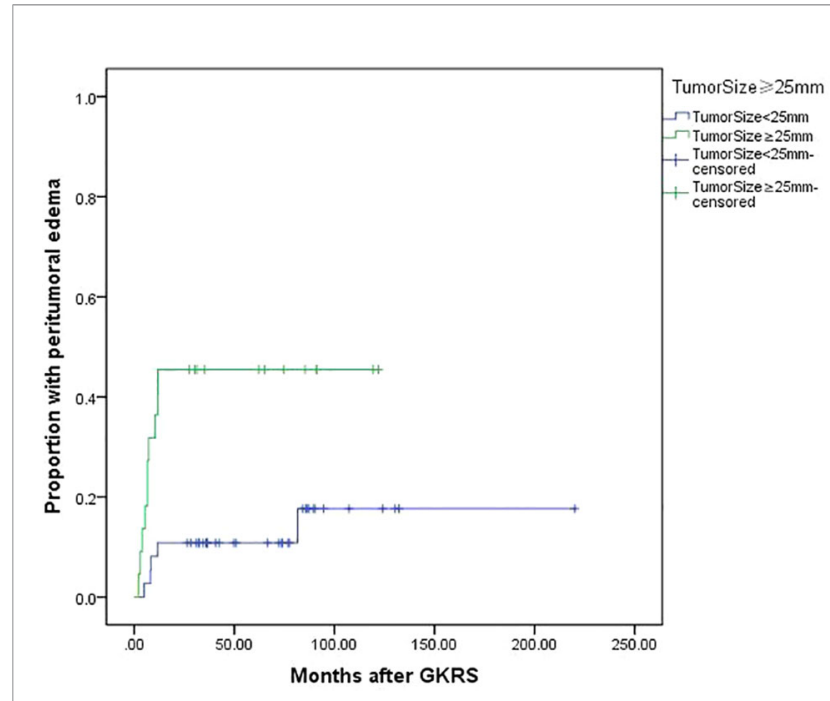

FIGURE 5 | Kaplan-Meier curve of peritumoral edema after GKRS of tumor size $\geq 25 \mathrm{~mm}$ vs. $<25 \mathrm{~mm}$. Tumor size $\geq 25 \mathrm{~mm}$ showed a higher peritumoral edema rate after GKRS ( $p=0.004)$.

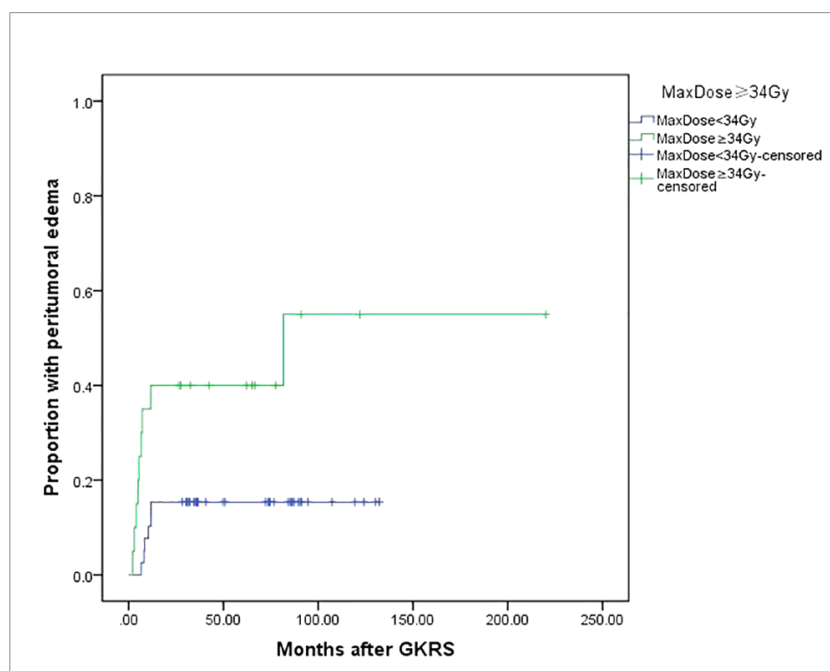

FIGURE 6 | Kaplan-Meier curve of peritumoral edema after GKRS of maximum dose $\geq 34$ Gy vs. $<34$ Gy. Maximum dose $\geq 34$ Gy showed a higher peritumoral edema rate after GKRS ( $p=0.005)$.

Sughrue et al. (17) performed a systematic review of 675 patients with untreated meningiomas followed with serial MR imaging from 22 studies. The authors found initial tumor diameter of 2$2.5 \mathrm{~cm}$ with the rapid growth of $>10 \%$ per year was prone to occur symptom progression at a rate of $42 \%$. They also found initial tumor diameter of $>2.5$ and $3 \mathrm{~cm}$ went on to develop new or worsened symptoms $17 \%$ of the time. In a recent metaanalyses, Nakasu et al. (12) also found large initial maximum diameter were significantly associated with symptomatic progression. As a high risk of symptom progression in large tumors, these patients may gain benefit from earlier treatment before the occurrence of symptoms.
TABLE 3 | Results of univariate and multivariate analysis for peritumoral edema after GKRS.

\begin{tabular}{|c|c|c|c|c|}
\hline \multirow[t]{2}{*}{ Variables } & \multicolumn{4}{|c|}{ Peritumoral edema after GKRS } \\
\hline & $\begin{array}{c}\text { Univariate, } \\
\text { p }\end{array}$ & $\begin{array}{c}\text { Multivariate, } \\
\text { p }\end{array}$ & HR & $95 \% \mathrm{Cl}$ \\
\hline Age ( $\geq 55$ years) & 0.935 & NA & NA & NA \\
\hline Sex (male vs female) & 0.855 & NA & NA & NA \\
\hline $\begin{array}{l}\text { Skull base vs non skull } \\
\text { base }\end{array}$ & 0.428 & NA & NA & NA \\
\hline $\begin{array}{l}\text { Tumor margin dose ( } \geq 14 \\
\text { Gy) }\end{array}$ & 0.100 & 0.477 & NA & NA \\
\hline$T V \geq 5.3 \mathrm{ml}$ & $0.038^{\star}$ & 0.118 & NA & NA \\
\hline Tumor size ( $\geq 25$ mm) & $0.004^{\star}$ & $0.026^{\star}$ & 3.461 & $\begin{array}{l}1.157- \\
10.356\end{array}$ \\
\hline Maximum dose ( $\geq 34$ Gy) & $0.005^{\star}$ & $0.037^{\star}$ & 3.067 & $1.068-8.809$ \\
\hline
\end{tabular}

$\mathrm{Cl}$, confidential interval; HR, hazards ratio; TV, tumor volume; NA, not available. ${ }^{*}$ Statistically significant $(P<0.05)$.

\section{Advantage and Limitation of Surgery}

Surgical resection has advantages of rapid tumor removal and histopathologic analysis. Recent European Association of NeuroOncology guidelines indicates that surgery is the first option when treatment is indicated in meningioma of any WHO grade (18). However, surgical resection is an invasive treatment, depends on tumor location and can cause significant morbidity (12). In the study of Naslund et al. (19), 30-day complication rate was significantly higher among the asymptomatic cases. Besides, asymptomatic meningioma patients were less likely to work full time after surgical resection as compared with preoperative status. Yano et al. (20) reported older patients (>70 years) had a higher complication rate after surgical for asymptomatic meningiomas than younger patients $(9.3 \%$ vs. $4.4 \%)$. For asymptomatic meningioma patients, surgical resection could make patients worse, at best unchanged (21). In the study of Jakola et al. (21), almost one in five patients developed subjective deterioration after surgery at a long-term follow up. Considering the potentially significant morbidity of surgery for asymptomatic meningiomas, surgical resection should be a more restrictive approach.

\section{Gamma Knife Radiosurgery for Asymptomatic Meningiomas}

A less invasive procedure, a low mortality and better function protection are the advantages of GKRS. These make GKRS more attractive and a preferred choice for asymptomatic meningiomas. A systematic review, meta-analysis and practice guideline (22) from international stereotactic radiosurgery society (ISRS) recommended radiosurgery may be proposed as a primary treatment modality for an asymptomatic or mildly symptomatic meningioma. Some authors $(7,10,14,15)$ had reported GKRS for asymptomatic meningiomas had a low tumor progression rate of $0 \%-5.9 \%$ and symptom progression rate of $2.6 \%-18 \%$, as well as an acceptable rate of complications. Table $\mathbf{4}$ summarizes recent literature reporting GKRS for asymptomatic meningiomas. Jo et al. (7) reported 69 asymptomatic meningiomas underwent GKRS with mean follow up of 63.0 months. The mean tumor diameter was 17.3 (range, 7-31 mm). The tumor control rate was $100 \%$ with median margin dose of 14.5 (range, 12-20) Gy. 
TABLE 4 | Literature review of GKRS for asymptomatic meningiomas.

\begin{tabular}{|c|c|c|c|c|c|c|c|}
\hline Study & $\begin{array}{c}\text { No. of } \\
\text { patients }\end{array}$ & $\begin{array}{l}\text { Median margin dose, } \\
\text { (range), Gy }\end{array}$ & $\begin{array}{c}\text { Median isodose line } \\
\text { (range), \% }\end{array}$ & $\begin{array}{l}\text { Imaging follow-up, } \\
\text { (months) }\end{array}$ & $\begin{array}{c}\text { Tumor } \\
\text { progression }\end{array}$ & $\begin{array}{l}\text { Symptom } \\
\text { progression }\end{array}$ & complications \\
\hline $\begin{array}{l}\text { Salvetti } \\
\text { et al. (14) }\end{array}$ & 42 & 15 (10-18) & $48(30-55)$ & Median 59 & $2.4 \%$ & $4.8 \%$ & $\begin{array}{l}2.4 \% \text { (permanent } \\
\text { neurological deficits) }\end{array}$ \\
\hline Jo et al. (7) & 69 & $14.5(12-20)$ & NA & Mean 63.0 & 0 & NA & $\begin{array}{l}39.1 \% \text { (transient } \\
\text { complications) }\end{array}$ \\
\hline $\begin{array}{l}\text { Kim et al. } \\
\text { (10) }\end{array}$ & 153 & $14(10-22)$ & $50(15-60)$ & Median 53 & $5.9 \%$ & $2.6 \%$ & $\begin{array}{l}\text { 13.3\% (mainly transient } \\
\text { complications) }\end{array}$ \\
\hline $\begin{array}{l}\text { Gupta } \\
\text { et al., (15) }\end{array}$ & 117 & $14(10-25)$ & $50(10-55)$ & Median 53 & $2.6 \%$ & $18 \%$ & $20.5 \%$ \\
\hline $\begin{array}{l}\text { Current } \\
\text { study }\end{array}$ & 59 & 13.0 (11.6-20.0) & $40(35-55)$ & Median 66.8 & $1.7 \%$ & $15.3 \%$ & $28.8 \%$ \\
\hline
\end{tabular}

GKRS, gamma knife radiosurgery.

Transient complications developed in $39.1 \%$ of patients. There was no patient developed permanent neurologic deficit. Salvetti et al. (14) reported a tumor progression rate of $2.4 \%$ and permanent neurological deficit rate of $2.4 \%$ in 42 asymptomatic meningiomas treated with GKRS with a median margin dose of 15 (10-18) Gy. In this study, $23.8 \%$ of patients were small tumor $(<20 \mathrm{~mm})$. The proportion of prior surgical resection and radiotherapy were $45.2 \%$ and $4.8 \%$ respectively. Kim et al. (10) reported efficacy of proactive GKRS $(n=153)$ in asymptomatic meningiomas compared with natural course $(n=201)$. The radiological PFS rates in GKRS and observation group were $94.4 \%$ and $38.5 \%$ at 5 years, and $88.5 \%$ and $7.9 \%$ at 10 years, respectively. Adverse events developed in $13.3 \%$ of patients treated with GKRS, including $0.5 \%$ of patients requiring surgery due to severe edema after GKRS. $15.7 \%$ of patients in GKRS group presented with peritumoral edema before GKRS, which was associated with adverse events after GKRS (HR 4.885, 95\% CI 1.660-14.376, $\mathrm{P}=0.004)$. In the study of Gupta et al. (15), 117 patients with 122 asymptomatic tumors were treated with GKRS with median dose of 14 (10-25) Gy. Thirty-nine percent of patients had prior surgical resection. Patients who presented with peritumoral edema were excluded. The radiological and clinical PFS were $97 \%$ and $86 \%$ at 5 years, $94.4 \%$ and $70 \%$ at 10 years, respectively. Neurological complications developed in $18 \%$ of patients.

In the current study, 59 asymptomatic meningiomas were treated with initial GKRS. Patients who presented with peritumoral edema were excluded. Two patients with small tumors $(<20 \mathrm{~mm})$ documented with tumor growth under radiological surveillance were included. One patient $(1.7 \%)$ experienced radiological progression. The PFS was $100 \%, 97 \%$ and $97 \%$ at 3, 5, and 10 years, respectively. Nine patients $(15.3 \%)$ occurred new neurological symptoms or signs after GKRS. The symptom PFS was $90 \%$ and $78 \%$ at 5 and 10 years respectively. Fifteen patients (25.4\%) occurred PTE after GKRS.

\section{Peritumoral Edema and Related Factors}

PTE is the most common adverse radiation effect after GKRS for meningiomas, which accounts for 15\%-28\% (23-30). Several clinical risk factors associated with PTE after GKRS had been reported, including sagittal sinus occlusion, parasagittal location, large tumor volume, presence of pretreatment edema, high radiation dose, high grade histology, and hemispheric tumor location (22-29). Kollová et al. (25) found significant risk factors associated with PTE after GKRS included tumor margin dose greater than $16 \mathrm{~Gy}$ and tumor volume greater than $10 \mathrm{~cm}^{3}$. Hoe et al. (31) reported $15.3 \%$ of patients developed new or increased PTE after GKRS, $8.8 \%$ of patients were symptomatic PTE. Pretreatment PTE, hemispheric tumor location and tumor volume larger than $4.2 \mathrm{cc}$ were associated with PTE.

PTE at diagnosis had been reported to be associated with highgrade meningiomas (32). Therefore, patients with pretreatment PTE were excluded in this study. The result in this study was similar with previous studies. 25.4\% of patients developed PTE after GKRS with median time of 7.2 (range, 2.0-81.6) months. Of this patients, seven cases $(11.9 \%)$ were symptomatic PTE. One patient received surgical resection for severe PTE. Univariate and multivariate analysis indicated large tumor size $(\geq 25 \mathrm{~mm})$ and maximum radiation dose ( $\geq 34$ Gy) were associated with PTE after GKRS.

\section{Study Limitations}

In this study, we restricted certain patients (large tumors, no PTE, and small tumors documented with growth) to undergo initial GKRS. This was a single-center retrospective study with selection and treatment biases. All of patients were diagnosed based on MRI or CT, and did not receive surgical resection before GKRS. Therefore, the histological diagnosis was not available. Besides, the number of patients in our study was small, which might affect statistical analysis. Finally, there was no control group to compare with those with natural course or treated with surgery.

\section{CONCLUSION}

In this single-center retrospective study, the results supported the efficacy and safety of initial GKRS for asymptomatic meningiomas. $98.3 \%$ of patients were under tumor control after GKRS. $15.3 \%$ of patients occurred new neurological symptoms or signs. For those large asymptomatic tumors or small tumors documented growth, initial GKRS could prevent tumor progression with an acceptable rate of complications. 
GKRS could be an alternative treatment modality for selected asymptomatic meningiomas.

\section{DATA AVAILABILITY STATEMENT}

The raw data supporting the conclusions of this article will be made available by the authors, without undue reservation.

\section{ETHICS STATEMENT}

The studies involving human participants were reviewed and approved by The Second Affiliated Hospital of Guangzhou Medical University Institutional Review Board. The patients/participants provided their written informed consent to participate in this study.

\section{REFERENCES}

1. Jadid KD, Feychting M, Hoijer J, Hylin S, Kihlstrom L, Mathiesen T. Long-term follow-up of incidentally discovered meningiomas. Acta Neurochir (Wien) (2015) 157(2):225-30; discussion 230. doi: 10.1007/s00701-014-2306-3

2. Kuratsu J, Kochi M, Ushio Y. Incidence and clinical features of asymptomatic meningiomas. J Neurosurg (2000) 92(5):766-70. doi: 10.3171/jns.2000.92.5.0766

3. Bondy M, Ligon BL. Epidemiology and etiology of intracranial meningiomas: a review. J Neurooncol (1996) 29(3):197-205. doi: 10.1007/BF00165649

4. Ostrom QT, Cioffi G, Gittleman H, Patil N, Waite K, Kruchko C, et al. CBTRUS Statistical Report: Primary Brain and Other Central Nervous System Tumors Diagnosed in the United States in 2012-2016. Neuro Oncol (2019) 21 (Suppl 5):v1-v100. doi: 10.1093/neuonc/noz150

5. Hashiba T, Hashimoto N, Izumoto S, Suzuki T, Kagawa N, Maruno M, et al. Serial volumetric assessment of the natural history and growth pattern of incidentally discovered meningiomas. J Neurosurg (2009) 110(4):675-84. doi: $10.3171 / 2008$.8.JNS08481

6. Oya S, Kim SH, Sade B, Lee JH. The natural history of intracranial meningiomas. J Neurosurg (2011) 114(5):1250-6. doi: 10.3171/2010.12.JNS101623

7. Jo KW, Kim CH, Kong DS, Seol HJ, Nam DH, Park K, et al. Treatment modalities and outcomes for asymptomatic meningiomas. Acta Neurochir (Wien) (2011) 153(1):62-7; discussion 7. doi: 10.1007/s00701-010-0841-0

8. Nakamura M, Roser F, Michel J, Jacobs C, Samii M. The natural history of incidental meningiomas. Neurosurgery (2003) 53(1):62-70; discussion -1. doi: 10.1227/01.neu.0000068730.76856.58

9. Yoneoka Y, Fujii Y, Tanaka R. Growth of incidental meningiomas. Acta Neurochir (Wien) (2000) 142(5):507-11. doi: 10.1007/s007010050463

10. Kim KH, Kang SJ, Choi JW, Kong DS, Seol HJ, Nam DH, et al. Clinical and radiological outcomes of proactive Gamma Knife surgery for asymptomatic meningiomas compared with the natural course without intervention. J Neurosurg (2018) 130:1-10. doi: 10.3171/2017.12.JNS171943

11. Agarwal V, McCutcheon BA, Hughes JD, Carlson ML, Glasgow AE, Habermann EB, et al. Trends in Management of Intracranial Meningiomas: Analysis of 49,921 Cases from Modern Cohort. World Neurosurg (2017) 106:145-51. doi: 10.1016/j.wneu.2017.06.127

12. Nakasu S, Nakasu Y. Natural History of Meningiomas: Review with Meta-analyses. Neurol Med Chir (2020) 60(3):109-20. doi: 10.2176/nmc.ra.2019-0213

13. Reinert M, Babey M, Curschmann J, Vajtai I, Seiler RW, Mariani L. Morbidity in 201 patients with small sized meningioma treated by microsurgery. Acta Neurochir (Wien) (2006) 148(12):1257-65; discussion 66. doi: 10.1007/ s00701-006-0909-z

14. Salvetti DJ, Nagaraja TG, Levy C, Xu Z, Sheehan J. Gamma Knife surgery for the treatment of patients with asymptomatic meningiomas. J Neurosurg (2013) 119(2):487-93. doi: 10.3171/2013.4.JNS121746

\section{AUTHOR CONTRIBUTIONS}

LW, CP, XY, HY, LC, and YD collected the data. JF, LW, CP, and XY analyzed the data. JY, JF, and LW wrote the paper. JY conceived and designed the study. All authors contributed to the article and approved the submitted version.

\section{FUNDING}

This work was supported by National Key Research and Development Project (grants number: 2017YFC0113700); National Natural Science Foundation of China (grants number: 81902928). China Postdoctoral Science Foundation Funded Project (2018M643343); Doctoral initiation project of Second Affiliated Hospital of Guangzhou medical university (010G271104).

15. Gupta A, Xu Z, Cohen-Inbar O, Snyder MH, Hobbs LK, Li C, et al. Treatment of Asymptomatic Meningioma With Gamma Knife Radiosurgery: Long-Term Follow-up With Volumetric Assessment and Clinical Outcome. Neurosurgery (2019) 85(5):E889-E99. doi: 10.1093/neuros/nyz126

16. Islim AI, Kolamunnage-Dona R, Mohan M, Moon RDC, Crofton A, Haylock $\mathrm{BJ}$, et al. A prognostic model to personalize monitoring regimes for patients with incidental asymptomatic meningiomas. Neuro Oncol (2020) 22(2):27889. doi: 10.1093/neuonc/noz160

17. Sughrue ME, Rutkowski MJ, Aranda D, Barani IJ, McDermott MW, Parsa AT. Treatment decision making based on the published natural history and growth rate of small meningiomas. J Neurosurg (2010) 113(5):1036-42. doi: $10.3171 / 2010.3$.JNS091966

18. Goldbrunner R, Minniti G, Preusser M, Jenkinson MD, Sallabanda K, Houdart E, et al. EANO guidelines for the diagnosis and treatment of meningiomas. Lancet Oncol (2016) 17(9):e383-91. doi: 10.1016/S1470-2045(16)30321-7

19. Naslund O, Skoglund T, Farahmand D, Bontell TO, Jakola AS. Indications and outcome in surgically treated asymptomatic meningiomas: a single-center case-control study. Acta Neurochir (Wien) (2020) 162. doi: 10.1007/s00701020-04244-6

20. Yano S, Kuratsu J. Kumamoto Brain Tumor Research G. Indications for surgery in patients with asymptomatic meningiomas based on an extensive experience. J Neurosurg (2006) 105(4):538-43. doi: 10.3171/jns.2006.105.4.538

21. Jakola AS, Gulati M, Gulati S, Solheim O. The influence of surgery on quality of life in patients with intracranial meningiomas: a prospective study. J Neurooncol (2012) 110(1):137-44. doi: 10.1007/s11060-012-0947-8

22. Marchetti M, Sahgal A, De Salles AAF, Levivier M, Ma L, Paddick I, et al. Stereotactic Radiosurgery for Intracranial Noncavernous Sinus Benign Meningioma: International Stereotactic Radiosurgery Society Systematic Review, Meta-Analysis and Practice Guideline. Neurosurgery (2020) 87. doi: 10.1093/neuros/nyaa169

23. Cai R, Barnett GH, Novak E, Chao ST, Suh JH. Principal risk of peritumoral edema after stereotactic radiosurgery for intracranial meningioma is tumorbrain contact interface area. Neurosurgery (2010) 66(3):513-22. doi: 10.1227/ 01.NEU.0000365366.53337.88

24. Chang JH, Chang JW, Choi JY, Park YG, Chung SS. Complications after gamma knife radiosurgery for benign meningiomas. J Neurol Neurosurg Psychiatry (2003) 74(2):226-30. doi: 10.1136/jnnp.74.2.226

25. Kollova A, Liscak R, Novotny J Jr., Vladyka V, Simonova G, Janouskova L. Gamma Knife surgery for benign meningioma. J Neurosurg (2007) 107 (2):325-36. doi: 10.3171/JNS-07/08/0325

26. Kuhn EN, Taksler GB, Dayton O, Loganathan A, Bourland D, Tatter SB, et al. Is there a tumor volume threshold for postradiosurgical symptoms? A singleinstitution analysis. Neurosurgery (2014) 75(5):536-45; discussion 44-5; quiz 45. doi: 10.1227/NEU.0000000000000519 
27. Lee SR, Yang KA, Kim SK, Kim SH. Radiation-induced intratumoral necrosis and peritumoral edema after gamma knife radiosurgery for intracranial meningiomas. J Korean Neurosurg Soc (2012) 52(2):98-102. doi: 10.3340/jkns.2012.52.2.98

28. Mansouri A, Larjani S, Klironomos G, Laperriere N, Cusimano M, Gentili F, et al. Predictors of response to Gamma Knife radiosurgery for intracranial meningiomas. J Neurosurg (2015) 123(5):1294-300. doi: 10.3171/2014.12.JNS141687

29. Novotny J Jr., Kollova A, Liscak R. Prediction of intracranial edema after radiosurgery of meningiomas. J Neurosurg (2006) 105 Suppl:120-6. doi: 10.3171/sup.2006.105.7.120

30. Singh VP, Kansai S, Vaishya S, Julka PK, Mehta VS. Early complications following gamma knife radiosurgery for intracranial meningiomas. J Neurosurg (2000) 93 Suppl 3:57-61. doi: 10.3171/jns.2000.93.supplement

31. Hoe Y, Choi YJ, Kim JH, Kwon DH, Kim CJ, Cho YH. Peritumoral Brain Edema after Stereotactic Radiosurgery for Asymptomatic Intracranial Meningiomas: Risks and Pattern of Evolution. J Korean Neurosurg Soc (2015) 58(4):379-84. doi: 10.3340/jkns.2015.58.4.379
32. Ressel A, Fichte S, Brodhun M, Rosahl SK, Gerlach R. WHO grade of intracranial meningiomas differs with respect to patient's age, location, tumor size and peritumoral edema. J Neurooncol (2019) 145(2):277-86. doi: 10.1007/s11060-019-03293-x

Conflict of Interest: The authors declare that the research was conducted in the absence of any commercial or financial relationships that could be construed as a potential conflict of interest.

Copyright (c) $2020 \mathrm{Fu}, \mathrm{Wu}$, Peng, Yang, You, Cao, Deng and Yu. This is an openaccess article distributed under the terms of the Creative Commons Attribution License (CC BY). The use, distribution or reproduction in other forums is permitted, provided the original author(s) and the copyright owner(s) are credited and that the original publication in this journal is cited, in accordance with accepted academic practice. No use, distribution or reproduction is permitted which does not comply with these terms. 